\title{
Timing of Metabolic Response Monitoring During Erlotinib Treatment in Non-Small Cell Lung Cancer
}

\author{
Matthijs H. van Gool ${ }^{1}$, Tjeerd S. Aukema ${ }^{1,2}$, Eva E. Schaake ${ }^{3}$, Herman Rijna ${ }^{4}$, Renato A. Valdés Olmos ${ }^{2}$, Renée van Pel ${ }^{5}$, \\ Sjaak A. Burgers ${ }^{3}$, Harm van Tinteren ${ }^{6}$, and Houke M. Klomp ${ }^{1}$, on behalf of the NEL Study Group \\ ${ }^{I}$ Department of Surgical Oncology, The Netherlands Cancer Institute-Antoni van Leeuwenhoek Hospital, Amsterdam, The Netherlands; \\ ${ }^{2}$ Department of Nuclear Medicine, The Netherlands Cancer Institute-Antoni van Leeuwenhoek Hospital, Amsterdam, The Netherlands; \\ ${ }^{3}$ Department of Thoracic Oncology, The Netherlands Cancer Institute-Antoni van Leeuwenhoek Hospital, Amsterdam, The Netherlands; \\ ${ }^{4}$ Department of Surgery, Kennemer Gasthuis, Haarlem, The Netherlands; ${ }^{5}$ Department of Pathology, The Netherlands Cancer Institute-Antoni \\ van Leeuwenhoek Hospital, Amsterdam, The Netherlands; and ${ }^{6}$ Department of Biometrics, The Netherlands Cancer Institute-Antoni van \\ Leeuwenhoek Hospital, Amsterdam, The Netherlands
}

The purpose of this study was to prospectively evaluate the timing of metabolic response monitoring with ${ }^{18} \mathrm{~F}-\mathrm{FDG}$ PET of (neoadjuvant) erlotinib treatment in patients with early-stage non-small cell lung cancer. Methods: This study was designed as an open-label phase II trial performed in 4 hospitals in The Netherlands. Patients received preoperative erlotinib (150 mg) once daily for $3 \mathrm{wk}$. Response evaluation was performed after $4-7 \mathrm{~d}$ and at $3 \mathrm{wk}$ with ${ }^{18} \mathrm{~F}-\mathrm{FDG}$ PET/CT scans. Tumor ${ }^{18} \mathrm{~F}-\mathrm{FDG}$ uptake and changes were measured as standardized uptake values (SUVs). The metabolic response was classified on the basis of European Organization for Research and Treatment of Cancer criteria ( $>25 \%$ decrease in the maximum SUV) and was compared with histopathologic regression as observed in the resection specimen. Results: From December 2006 to November 2010, 60 patients with non-small cell lung cancer eligible for surgical resection were enrolled in this study. For 43 patients ( 18 men and 25 women), baseline ${ }^{18}$ F-FDG PET/CT scans as well as both monitoring scans and histopathologic response monitoring were available. A partial metabolic response on ${ }^{18} \mathrm{~F}-\mathrm{FDG}$ PET/CT scans was observed for 10 patients (23\%) after $1 \mathrm{wk}$ and for 14 patients (33\%) after 3 wk. Histopathologic examination revealed regression (necrosis of $>50 \%$ ) in 11 patients (26\%). In these patients, the maximum SUV decreased by a mean of $17 \%$ within $1 \mathrm{wk}$ and a mean of $31 \%$ at $3 \mathrm{wk}$. Seven patients were identified as responders within $1 \mathrm{wk}$. Conclusion: Response monitoring with ${ }^{18} \mathrm{~F}-\mathrm{FDG}$ PET/CT within 1 wk after the start of erlotinib treatment identified approximately $64 \%$ of histopathologic responders on the basis of European Organization for Research and Treatment of Cancer criteria.

Key Words: molecular biology; oncology; PET/CT; epidermal growth; non-small cell lung carcinoma

J Nucl Med 2014; 55:1081-1086

DOI: 10.2967/jnumed.113.130674

$\mathbf{R}$ ecent advances in targeted therapy have provided novel treatment options for non-small cell lung cancer (NSCLC) (1).

Received Aug. 30, 2013; revision accepted Mar. 14, 2014.

For correspondence or reprints contact: Houke M. Klomp, Department of Surgical Oncology, The Netherlands Cancer Institute-Antoni van Leeuwenhoek

Hospital, Plesmanlaan 121, 1066 CX Amsterdam, The Netherlands.

E-mail: h.klomp@nki.nl

Published online May 8, 2014

COPYRIGHT (C 2014 by the Society of Nuclear Medicine and Molecular Imaging, Inc.
The epidermal growth factor receptor (EGFR) is overexpressed or may harbor activating mutations, mainly in adenocarcinoma. EGFR tyrosine kinase inhibitors (TKIs), such as erlotinib, can block the catalytic activity of this enzyme, which is involved in tumor cell proliferation, angiogenesis, invasion, and metastasis $(2,3)$. The probability of a response to EGFR TKIs is considerably higher in patients who have tumors with EGFR mutations (4-6). However, the prediction of a response by mutation analysis only is suboptimal $(7,8)$. It is known that some patients without apparent sensitizing EGFR mutations do benefit from erlotinib therapy (9), perhaps because of heterogeneity within tumors or the limitation of biopsy analysis not always showing relevant mutations. On the other hand, patients who do not respond to EGFR TKIs, despite the presence of activating mutations, could be spared unnecessary toxicity and costs.

Metabolic imaging of NSCLC and several other tumor types has been shown to be valuable in response assessment in the setting of targeted therapy (10-14). ${ }^{18} \mathrm{~F}$-FDG PET/CT provides information about tumor metabolic activity, which may be useful for monitoring molecular changes associated with the treatment response $(15,16)$. An early assessment of the tumor response with ${ }^{18} \mathrm{~F}$-FDG PET/CT performed during therapy was recently proposed as a criterion for treatment modulation or modification $(17,18)$. Early decision making about the effect of treatment can help avoid overtreatment or ineffective treatment, lower health care costs, reduce side effects and, ultimately, improve outcomes $(17,19,20)$.

This phase II study was designed to evaluate the timing of metabolic response monitoring with ${ }^{18} \mathrm{~F}-\mathrm{FDG}$ PET/CT of neoadjuvant erlotinib treatment of patients with NSCLC before surgery. Response evaluation was performed within $1 \mathrm{wk}$ of the initiation of treatment and after $3 \mathrm{wk}$ of treatment. In addition to evaluation of the timing of metabolic response monitoring during erlotinib treatment, another study objective was to relate the data to the histopathologic response in patients with NSCLC.

\section{MATERIALS AND METHODS}

\section{Study Design}

The study design, eligibility criteria, and treatment schedule have been described in detail elsewhere (20). In short, this study was designed as an open-label, noncomparative phase II trial performed in 4 hospitals in The Netherlands and was approved by each local independent ethics committee and institutional review board (or equivalent). All patients signed a written informed consent form before the start of the study treatment. 
Patients with newly diagnosed resectable NSCLC, that is, clinical T1-T3 N0-N1, were allowed to enter the study. The primary lesion had to be measurable, that is, the longest diameter had to be greater than or equal to $1 \mathrm{~cm}$ as measured by a spiral CT scan. Sixty patients received 1 tablet of erlotinib $(150 \mathrm{mg})$ daily during an intended course of 3 wk. Surgical resection was scheduled for the fourth week after the start of treatment.

\section{Imaging Data}

PET/CT imaging was performed with a hybrid system (GeminiTF; Philips) $60 \mathrm{~min}$ after ${ }^{18} \mathrm{~F}$-FDG injection. ${ }^{18} \mathrm{~F}$-FDG was administered in dosages of 180-240 MBq. Patients fasted for $6 \mathrm{~h}$ before imaging. Diabetes mellitus was regulated in advance (plasma glucose level of $<10 \mathrm{mmol} / \mathrm{L}$ ). The interval between ${ }^{18} \mathrm{~F}$-FDG administration and scanning was $60 \mathrm{~min}$ ( $\pm 10 \mathrm{~min}$ ). Low-dose CT images (40 mAs; 5-mm slices) were acquired without intravenous contrast material.

The images generated (PET/CT, low-dose CT, and PET) were displayed with an OsiriX DICOM Viewer (Pixmeo) in a Unix-based operating system (Mac Pro; Apple) and were evaluated on the basis of 2-dimensional orthogonal reslicing. The images were evaluated by 1 nuclear physician. ${ }^{18} \mathrm{~F}$-FDG PET/CT imaging was evaluable only when scans were acquired with the same scanner, acquisition protocol, and reconstruction software and with similar intervals from tracer injection to scanning.

A baseline ${ }^{18}$ F-FDG PET/CT scan was obtained during routine staging for all patients. The baseline ${ }^{18} \mathrm{~F}-\mathrm{FDG}$ PET/CT scan had to be acquired within 1 mo before the start of erlotinib treatment. For early monitoring, the ${ }^{18}$ F-FDG PET/CT scan was planned for within 7 $\mathrm{d}$ after the initiation of erlotinib therapy. For late monitoring, the ${ }^{18} \mathrm{~F}$ FDG PET/CT scan was planned for about $21 \mathrm{~d}$ after the initiation of erlotinib therapy. All metabolic data were compared with the patient's baseline data.

\section{Assessment of Metabolic Response}

All imaging data were sent to The Netherlands Cancer InstituteAntoni van Leeuwenhoek Hospital, Amsterdam, The Netherlands, for review and analyses. ${ }^{18} \mathrm{~F}$-FDG PET/CT scans obtained during and after treatment with erlotinib were compared with baseline ${ }^{18} \mathrm{~F}-\mathrm{FDG}$ PET/CT scans. ${ }^{18} \mathrm{~F}-\mathrm{FDG}$ tumor uptake was quantified as the maximum standardized uptake value $\left(\mathrm{SUV}_{\max }\right.$; the maximum activity concentration of ${ }^{18} \mathrm{~F}$-FDG divided by the injected dose and corrected for the body weight of the patient). For determination of the $\mathrm{SUV}_{\max }$, the volume of the primary tumor was searched for the maximum ${ }^{18} \mathrm{~F}-\mathrm{FDG}$ uptake. Regions of interest were manually drawn. The metabolic response was assessed on the basis of European Organization for Research and Treatment of Cancer (EORTC) criteria for a tumor response (21). In short, progressive metabolic disease was classified as an increase in the $\mathrm{SUV}_{\max }$ of more than $25 \%$, stable metabolic disease was classified as an increase or a decrease in the $\mathrm{SUV}_{\max }$ of less than $25 \%$, and a partial metabolic response was classified as a reduction in the $\mathrm{SUV}_{\max }$ of at least $25 \%$.

\section{Histopathologic Assessment}

From formalin-fixed resection specimens, areas with macroscopically viable tumor tissue were embedded in paraffin, and serial sections were stained with hematoxylin and eosin. The samples were scored for residual vital tumor tissue and the presence of morphologic signs of therapy-induced regression, such as necrosis with foam cell reaction, giant cell reaction, cholesterol clefts, and fibrotic alterations (classification of Junker et al. (22)) For reporting in this study, a cutoff of $50 \%$ necrosis (with morphologic signs of therapy-induced regression) was used for a partial histopathologic response. When more than $90 \%$ necrosis was present in a resection specimen, tumor regression was defined as a nearly complete histopathologic response. One pathologist evaluated all of the resection specimens and was unaware of other patient data. Testing for EGFR and K-ras mutations was performed at the certified laboratory of The Netherlands Cancer Institute-Antoni van Leeuwenhoek Hospital, Amsterdam, The Netherlands, as described by van Zandwijk et al. (2).

\section{Statistical Considerations}

The association of the timing of an early ${ }^{18} \mathrm{~F}-\mathrm{FDG} \mathrm{PET} / \mathrm{CT}$ scan and relative changes in the $\mathrm{SUV}_{\text {max }}$ was tested with a linear-by-linear association test. The association of relative changes in the $\mathrm{SUV}_{\max }$ and a histopathologic response was tested with a linear-by-linear association test. Differences in $\mathrm{SUV}_{\max }$ measurements according to EGFR mutation status were tested with a Kruskal-Wallis test. All analyses were performed with $\mathrm{R}$ version 2.152 .

\section{RESULTS}

From December 2006 to November 2010, 60 patients with NSCLC eligible for surgical resection entered the study. A patient flow diagram is shown in Figure 1. For 43 patients (18 men and 25 women), both early and late ${ }^{18} \mathrm{~F}$-FDG PET/CT scans were obtained, and histopathologic evaluation was available as well. The median age of the patients was $65 \mathrm{y}$ (range, 36-76 y). Patients received a median treatment of $20 \mathrm{~d}$ (range, 9-27 d). General patient characteristics are shown in Table 1.

The median $\mathrm{SUV}_{\max }$ at the baseline ${ }^{18} \mathrm{~F}-\mathrm{FDG}$ PET/CT scan was 9.1 (range, 1.8-24.3). Early ${ }^{18}$ F-FDG PET/CT scans were obtained after a median treatment of $6 \mathrm{~d}$ (range, 2-11d). The median $\mathrm{SUV}_{\max }$ at the early scans was 8.5 (range, 0.7-24.0). Later ${ }^{18}$ F-FDG PET/CT scans were obtained after a median of $21 \mathrm{~d}$ (range, 14-33 d). The median $\mathrm{SUV}_{\text {max }}$ at the later scans was 8.1 (range, 0.6-22.7). The absolute $\mathrm{SUV}_{\max }$ at the later ${ }^{18}$ F-FDG PET/CT scans was highly correlated with the absolute $\mathrm{SUV}_{\max }$ at the early ${ }^{18} \mathrm{~F}$-FDG

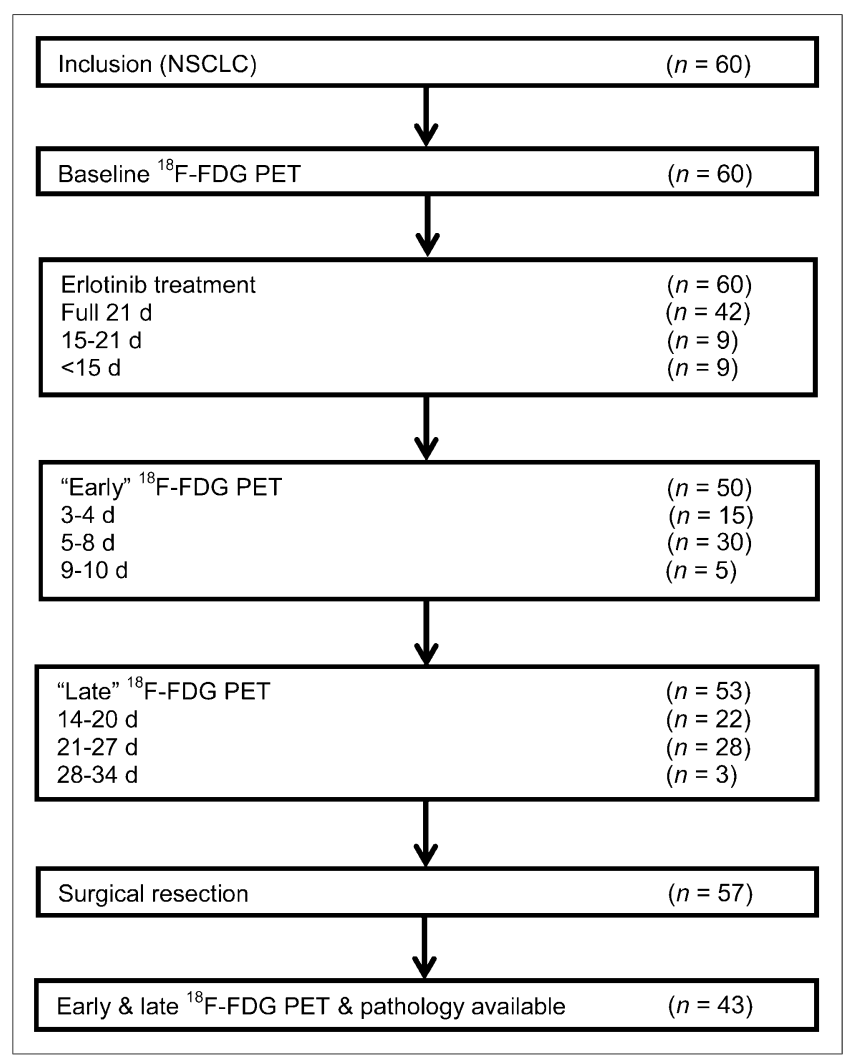

FIGURE 1. Patient flow diagram. 
TABLE 1

Characteristics of 43 Patients

\begin{tabular}{|c|c|c|c|}
\hline Characteristic & No. & Percentage & Range \\
\hline Men/women & $18 / 25$ & $42 / 58$ & \\
\hline Mean age at diagnosis (y) & 63 & & $36-76$ \\
\hline \multicolumn{4}{|l|}{ Smoking status } \\
\hline Never & 12 & 28 & \\
\hline Former & 20 & 46 & \\
\hline Current & 11 & 26 & \\
\hline \multicolumn{4}{|l|}{ Clinical stage } \\
\hline IA & 12 & 28 & \\
\hline IB & 16 & 37 & \\
\hline IIA & 6 & 14 & \\
\hline IIB & 3 & 7 & \\
\hline$\geq 111 \mathrm{~A}$ & 6 & 14 & \\
\hline \multicolumn{4}{|l|}{ Mutation status } \\
\hline EGFR & 5 & 12 & \\
\hline Exon 19 & 4 & 10 & \\
\hline Exon 21 & 1 & 2 & \\
\hline K-ras & 8 & 19 & \\
\hline \multicolumn{4}{|l|}{$\begin{array}{l}\text { Metabolic data } \\
\quad(\text { median SUV } \text { max }) \text { at: }\end{array}$} \\
\hline Baseline & 9.1 & & $1.8-24.3$ \\
\hline Early scan & 8.5 & & $0.7-24.0$ \\
\hline Later scan & 8.1 & & $0.6-22.7$ \\
\hline
\end{tabular}

PET/CT scans $(0.91 ; P<0.001)$. SUV $_{\max }$ data for individual patients are shown in Figure 2.

At the early ${ }^{18} \mathrm{~F}$-FDG PET/CT scan (within $1 \mathrm{wk}$ ), 20 patients showed a relative decrease in the $\mathrm{SUV}_{\max }$ ranging from $63 \%$ to $2 \%$. No change or an increase in the $\mathrm{SUV}_{\max }$ ranging from $0 \%$ to $75 \%$ was seen in 23 patients. The relative change in the $S_{U V} V_{\max }$ showed no significant correlation with the timing of the early ${ }^{18} \mathrm{~F}$ FDG PET/CT scan $(P=0.78)$. At later monitoring, 27 patients showed a decrease in the $\mathrm{SUV}_{\text {max }}$ ranging from $78 \%$ to $5 \%$. Sixteen patients showed an increase in the $\mathrm{SUV}_{\max }$ ranging from $1 \%$ to $74 \%$. The relative change in the $\mathrm{SUV}_{\max }$ at the early ${ }^{18} \mathrm{~F}-\mathrm{FDG}$ PET/CT scan (compared with the baseline) showed a significant correlation with the relative change in the $\mathrm{SUV}_{\max }$ at the later ${ }^{18} \mathrm{~F}$ FDG PET/CT scan $(0.82 ; P<0.001)$ (Fig. 3$)$. Of the 20 patients with a decrease in the $\mathrm{SUV}_{\max }$ within $1 \mathrm{wk}$, only 1 patient showed a later increase above the baseline level (22\%).

Table 2 shows the metabolic data at early and later scans according to EORTC criteria. None of the patients with progressive metabolic disease at the early ${ }^{18} \mathrm{~F}$-FDG PET/CT scan showed a significant decrease in the $\mathrm{SUV}_{\max }$ at the later scan. At early monitoring, 10 patients (23\%) showed a partial metabolic response (decrease in the $\mathrm{SUV}_{\max }$ of more than 25\%). After $3 \mathrm{wk}, 14$ patients $(33 \%)$ were classified as responders; 9 of them had been identified at early monitoring. The median percentage of tumor necrosis in the resection specimens was $30 \%$ (range, $0 \%-97 \%$ ). In 3 patients (7\%), more than $90 \%$ tumor necrosis was seen. Tumor specimens from 8 patients (19\%) showed 50\%-90\% tumor necrosis. In the resection specimens from 32 patients (74\%), less than 50\% tumor necrosis was seen.

Figures 4 and 5 show the relative change in the SUV $\mathrm{Sax}_{\max }$ according to the histopathologic response at both early and later scans. In patients with more than $50 \%$ tumor necrosis, the $\mathrm{SUV}_{\max }$ decreased by a mean of $17 \%$ within $1 \mathrm{wk}$ and a mean of $31 \%$ at $3 \mathrm{wk}$.

Of the patients for whom the early ${ }^{18}$ F-FDG PET/CT scan indicated progressive disease, none had a significant later metabolic response or histopathologic response ( $>50 \%$ necrosis).

There was no significant difference in ${ }^{18} \mathrm{~F}-\mathrm{FDG}$ uptake at baseline between EGFR-positive and EGFR-negative tumors (mean $\pm \mathrm{SD}$, $9.1 \pm 4.6$ and $9.9 \pm 5.3$, respectively; $P=0.74$ ). All 5 patients who had tumors with EGFR mutations showed a metabolic response at the early scan, and 4 patients also showed a response at the later scan (1 patient discontinued erlotinib after $13 \mathrm{~d}$ because of toxicity). ${ }^{18}$ F-FDG uptake in tumors with EGFR mutations decreased to a mean $\mathrm{SUV}_{\text {max }}$ of $5.7(\mathrm{SD}, 2.8)$ at the early scan and a mean $\mathrm{SUV}_{\max }$ of $4.0(\mathrm{SD}, 2.5)$ at the later scan $(P=0.004)$.

\section{DISCUSSION}

The results of the present study showed that a change in metabolic activity within $1 \mathrm{wk}$ after the initiation of erlotinib treatment is informative for a histopathologic response after $3 \mathrm{wk}$ of treatment. A decrease in metabolic activity within $1 \mathrm{wk}$ likely will continue after $3 \mathrm{wk}$ of therapy (94\%). On the other hand, an increase in the $\mathrm{SUV}_{\text {max }}$ during the first week will persist in most patients, suggesting ineffective treatment.

Although screening after 3 wk revealed 5 more patients with a partial metabolic response than screening after $1 \mathrm{wk}$, a partial histopathologic response was seen in the resection specimen from only 1 of these patients. In addition, 1 other patient had a partial metabolic response at the early ${ }^{18} \mathrm{~F}$-FDG PET/CT scan and stable metabolic disease at the late ${ }^{18} \mathrm{~F}-\mathrm{FDG}$ PET/CT scan. In this patient, erlotinib treatment was discontinued because of side effects. Furthermore, 4 of the 23 patients with no change or an increase in the $\mathrm{SUV}_{\text {max }}$ at the early ${ }^{18} \mathrm{~F}$-FDG PET/CT scan showed a partial histopathologic response, of which only 1 patient with a partial metabolic response was identified at the later scan.

The metabolic response did not exactly correspond to histopathologic regression of the tumor. ${ }^{18} \mathrm{~F}-\mathrm{FDG}$ uptake on PET may reflect various tissue reactions, such as tumor progression or regression, as well as senescence, fibrosis formation, and inflammatory reactions such as macrophage infiltration. Pathologic evaluation of (residual) tumor tissue after targeted treatment is also challenging. Although some pathologic reports have described criteria for a response to neoadjuvant treatment based on necrosis, fibrosis, and regression, a gold
FIGURE 2. (A) Relative change in SUV $V_{\max }$ data for individual patients with decrease in SUV max $_{\text {max }}$ on early scan. Baseline $S_{U} V_{\max }$ (set as 0 ) and data from early and later scans are shown. (B) Relative change in SUV $V_{\max }$ data for individual patients with increase in SUV $V_{\max }$ on early scan. Baseline SUV $V_{\max }$ (set as 0) and data from early and later scans are shown.

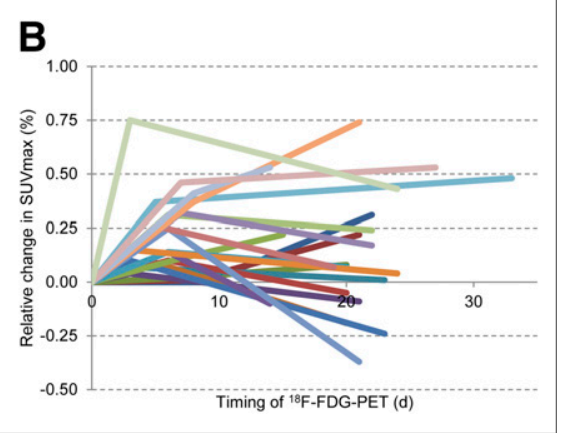

Monitoring of NeoAduUvant Erlotinib • van Gool et al. 


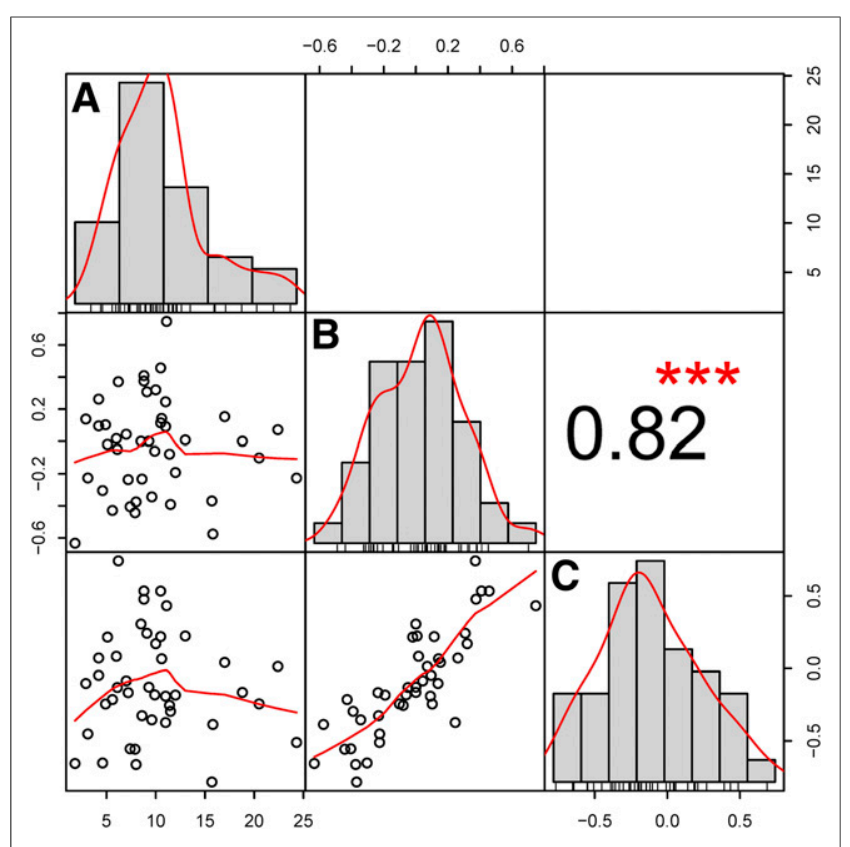

FIGURE 3. Correlation matrix for (relative) $S U V_{\max }$ (A) Distribution of absolute SUV $_{\max }$ at baseline. (B and C) Distributions of relative changes in $\mathrm{SUV}_{\max }$ at $1 \mathrm{wk}(\mathrm{B})$ and $3 \mathrm{wk}(\mathrm{C}) .{ }^{\star \star \star} P<0.001$.

standard for classifying regression in response to TKI therapy is lacking. A response to erlotinib can be expected to develop within several weeks, but apoptosis, transitioning of necrosis to fibrosis, and inflammatory and granulomatous reactions are difficult to quantify. Because some spontaneous necrosis exists in most NSCLCs, a cautious cutoff of more than $50 \%$ necrosis was used for a pathologic response (20).

Despite the heterogeneous and metabolically dynamic nature of the tumor, the results of the present study showed that additional screening after $3 \mathrm{wk}$ seems to have less value. Therefore, for patients with no change or an increase in the $\mathrm{SUV}_{\max }$ on early ${ }^{18} \mathrm{~F}-\mathrm{FDG}$ PET/CT scans, TKI treatment could be discontinued and surgery could be advanced. Adequate early treatment monitoring has several advantages. Patients who do not benefit from therapy are only exposed to potential toxicity for a short period of time (20). In addition, the successes of new therapeutic agents have led to increases in health care costs that are causing serious financial

TABLE 2

Responses at Early and Later ${ }^{18}$ F-FDG PET/CT Scans According to EORTC Criteria

\begin{tabular}{lcrcc}
\hline \multirow{2}{*}{$\begin{array}{c}\text { Early response } \\
( \pm 1 \mathrm{wk})\end{array}$} & \multicolumn{4}{c}{ Later response $( \pm 3 \mathrm{wk})$} \\
\cline { 2 - 5 } & $\mathrm{PMR}$ & \multicolumn{1}{c}{ SMD } & PMD & Total \\
\hline PMR & $9(90 \%)$ & $1(10 \%)$ & $0(0 \%)$ & $10(23 \%)$ \\
SMD & $5(20 \%)$ & $19(76 \%)$ & $1(4 \%)$ & $23(58 \%)$ \\
PMD & $0(0 \%)$ & $3(38 \%)$ & $5(62 \%)$ & $8(19 \%)$ \\
Total & $14(33 \%)$ & $23(53 \%)$ & $6(14 \%)$ & $43(100 \%)$
\end{tabular}

PMR = partial metabolic response, defined as reduction in SUV $_{\max }$ of more than $25 \%$; SMD = stable metabolic disease; $\mathrm{PMD}=$ progressive metabolic disease. burdens for patients, hospitals, and society (23). With early assessment, the futile use of medications can be avoided, and patients who do not respond to EGFR TKIs may be given other, more effective treatments $(24,25)$. In our series, early screening for no change or an increase in the $\mathrm{SUV}_{\max }$ on ${ }^{18} \mathrm{~F}$-FDG PET/CT will result in a discontinuation of TKI therapy for $53 \%$ of the patients.

To our knowledge, the present study is the first to analyze the timing of monitoring of the metabolic response to neoadjuvant targeted therapy in early-stage lung cancer and the relationship with pathologic signs of regression. Several other investigations have demonstrated the value of early metabolic monitoring (days 7-14) for predicting progression-free survival and overall survival in advanced-stage disease. Our data are in line with those of Zander et al. (19) and O'Brien et al. (26), who showed that early monitoring can predict the metabolic response at a later scan after erlotinib treatment in patients with advanced NSCLC.

For categorization of the metabolic response, we used EORTC criteria (25\% decrease in the $\mathrm{SUV}_{\max }$ ). One could argue that this cutoff might be suboptimal for early assessment (within 1 wk of treatment initiation). Takahashi et al. (27) used ${ }^{18} \mathrm{~F}-\mathrm{FDG}$ PET/CT for gefitinib response monitoring after $2 \mathrm{~d}$ and 1 mo of treatment of 20 patients with advanced lung adenocarcinoma and suggested a cutoff of $20 \%$ for a decrease in the $\mathrm{SUV}_{\max }$ at early monitoring. However, the size of the study did not permit testing of other cutoff values.

In our series, there was large variability in the timing of the ${ }^{18} \mathrm{~F}$ FDG PET/CT studies because of difficulties in scheduling and therefore in adherence to the protocol. However, our analyses regarding the timing of the studies revealed no difference in correlation between early and later metabolic responses. The observed changes in the $\mathrm{SUV}_{\max }$ were above and beyond variations or errors (28). Other limitations of the study were the lack of an untreated control group and the fact that some patients did not complete the planned treatment course of $21 \mathrm{~d}$ because of toxicity.

Nevertheless, our data showed that response monitoring with ${ }^{18}$ F-FDG PET/CT has great potential for targeted treatment and

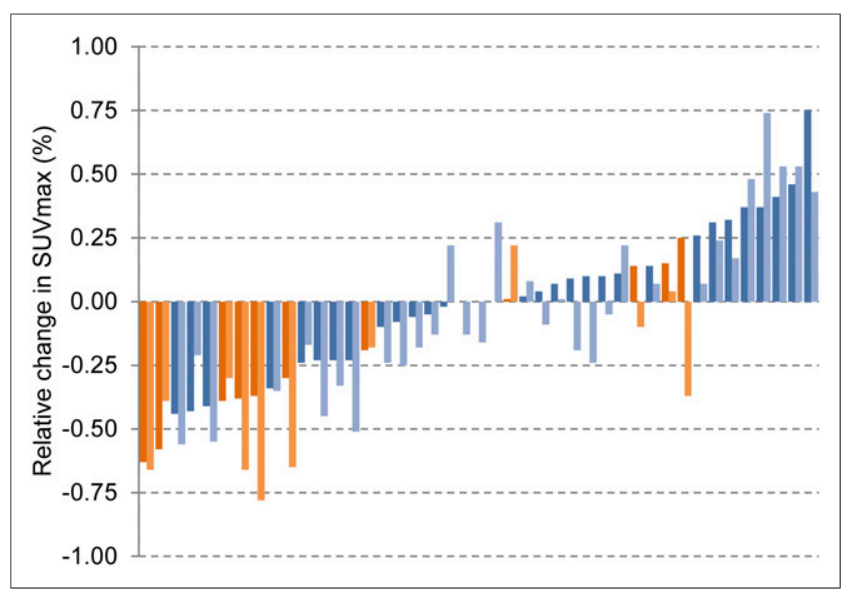

FIGURE 4. Waterfall plot of individual relative change in $\mathrm{SUV}_{\max }$ according to histopathologic response. Dark orange bars show relative change in SUV $_{\max }$ at early ${ }^{18} \mathrm{~F}$-FDG PET/CT scan in patients with pathologic response. Light orange bars show relative change in $S U V_{\max }$ at late ${ }^{18} \mathrm{~F}-\mathrm{FDG} \mathrm{PET} / \mathrm{CT}$ scan in patients with pathologic response. Dark blue bars show relative change in SUV $V_{\max }$ at early ${ }^{18} \mathrm{~F}$-FDG PET/CT scan in patients without pathologic response. Light blue bars show relative change in SUV ${ }_{\max }$ at late ${ }^{18} \mathrm{~F}-\mathrm{FDG}$ PET/CT scan in patients without pathologic response. 


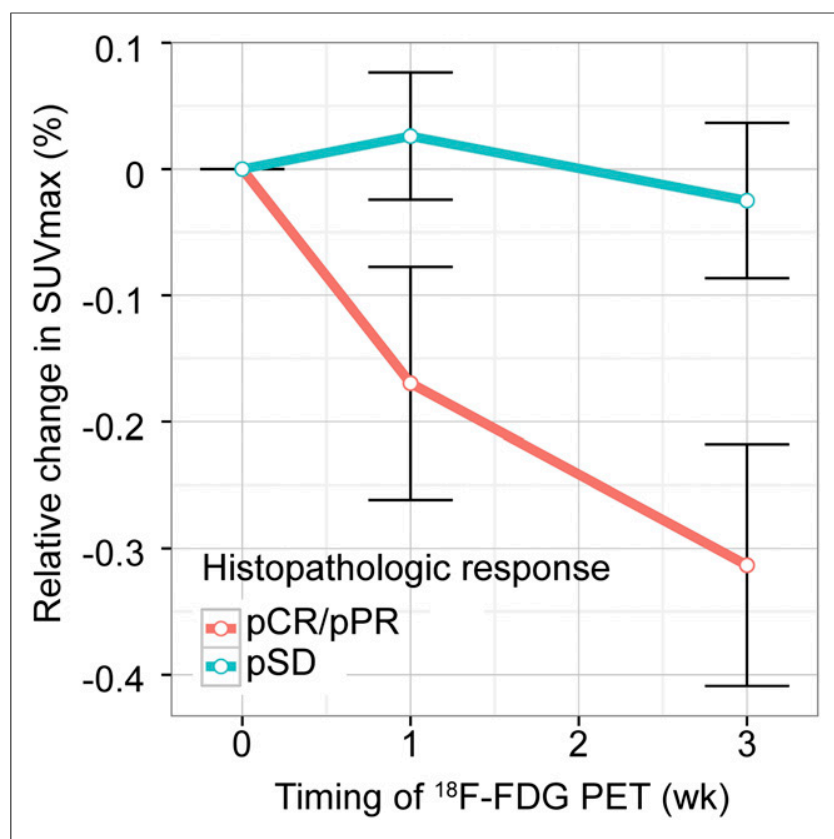

FIGURE 5. Relative change in SUV $\mathrm{max}_{\text {ax }}$ according to histopathologic response. $\mathrm{pCR}=$ more than $90 \%$ tumor necrosis; pPR $=50 \%-90 \%$ necrosis; $\mathrm{PSD}=$ less than $50 \%$ necrosis.

can be performed as early as $1 \mathrm{wk}$ after the initiation of treatment. Patients with a substantial decrease in metabolic activity during erlotinib treatment probably will benefit from continued treatment. Metabolic cutoff values may be optimized.

\section{CONCLUSION}

Response monitoring with ${ }^{18} \mathrm{~F}-\mathrm{FDG}$ PET/CT scans within $1 \mathrm{wk}$ after the start of erlotinib treatment identified most histopathologic responders. A decrease in metabolic activity within $1 \mathrm{wk}$ is likely to continue after $3 \mathrm{wk}$ of therapy. Therefore, an additional ${ }^{18} \mathrm{~F}-\mathrm{FDG}$ PET/CT scan after 3 wk of treatment seems to have less value.

\section{DISCLOSURE}

The costs of publication of this article were defrayed in part by the payment of page charges. Therefore, and solely to indicate this fact, this article is hereby marked "advertisement" in accordance with 18 USC section 1734 . This phase II study was an investigatorinitiated study supported by an unrestricted educational grant from Roche, The Netherlands. No other potential conflict of interest relevant to this article was reported.

\section{ACKNOWLEDGMENTS}

We thank the staff of the data center at The Netherlands Cancer Institute for data management and logistic support. The members of the NEL Study Group are as follows: Houke M. Klomp, $\mathrm{MD}, \mathrm{PhD}$, Department of Surgical Oncology, The Netherlands Cancer Institute-Antoni van Leeuwenhoek Hospital, Amsterdam, The Netherlands; I. Kappers, MD, Department of Surgical Oncology, The Netherlands Cancer Institute-Antoni van Leeuwenhoek Hospital, Amsterdam, The Netherlands; M.W. Wouters, MD, PhD, Department of Surgical Oncology, The Netherlands Cancer Institute-Antoni van Leeuwenhoek Hospital, Amsterdam, The Netherlands; Eva E. Schaake, MD, Department of Thoracic Oncology, The Netherlands
Cancer Institute-Antoni van Leeuwenhoek Hospital, Amsterdam, The Netherlands; Tjeerd S. Aukema, MD, PhD, Department of Surgical Oncology, The Netherlands Cancer Institute-Antoni van Leeuwenhoek Hospital, Amsterdam, The Netherlands; N. van Zandwijk, $\mathrm{MD}, \mathrm{PhD}$, Department of Thoracic Oncology, The Netherlands Cancer Institute-Antoni van Leeuwenhoek Hospital, Amsterdam, The Netherlands; Sjaak A. Burgers, MD, PhD, Department of Thoracic Oncology, The Netherlands Cancer Institute-Antoni van Leeuwenhoek Hospital, Amsterdam, The Netherlands; P. Baas, MD, PhD, Department of Thoracic Oncology, The Netherlands Cancer InstituteAntoni van Leeuwenhoek Hospital, Amsterdam, The Netherlands; M. van den Heuvel, MD, PhD, Department of Thoracic Oncology, The Netherlands Cancer Institute-Antoni van Leeuwenhoek Hospital, Amsterdam, The Netherlands; W. Buikhuisen, MD, Department of Thoracic Oncology, The Netherlands Cancer Institute-Antoni van Leeuwenhoek Hospital, Amsterdam, The Netherlands; Renato A. Valdés Olmos, MD, PhD, Department of Nuclear Medicine, The Netherlands Cancer Institute-Antoni van Leeuwenhoek Hospital, Amsterdam, The Netherlands; H.J. Teertstra, MD, Department of Radiology, The Netherlands Cancer Institute-Antoni van Leeuwenhoek Hospital, Amsterdam, The Netherlands; D. de Jong, MD, PhD, Department of Pathology, The Netherlands Cancer Institute-Antoni van Leeuwenhoek Hospital, Amsterdam, The Netherlands; Renée van Pel, MD, Department of Pathology, The Netherlands Cancer InstituteAntoni van Leeuwenhoek Hospital, Amsterdam, The Netherlands; Harm van Tinteren, PhD, Department of Biometrics, The Netherlands Cancer Institute-Antoni van Leeuwenhoek Hospital, Amsterdam, The Netherlands; O. Dalesio, PhD, Department of Biometrics, The Netherlands Cancer Institute-Antoni van Leeuwenhoek Hospital, Amsterdam, The Netherlands; Herman Rijna, MD, PhD, Department of Thoracic Surgery, Kennemer Gasthuis, Haarlem, The Netherlands; C. Weenink, MD, Department of Pulmonology, Kennemer Gasthuis, Haarlem, The Netherlands; A. Dingemans, MD, PhD, Department of Pulmonology, Maastricht Academic Medical Centre, Maastricht, The Netherlands; J. Brahim, MD, Department of Pulmonology, Haga Hospital, The Hague, The Netherlands; and H.E. Codrington, MD, Department of Pulmonology, Haga Hospital, The Hague, The Netherlands.

\section{REFERENCES}

1. Soria JC, Mok TS, Cappuzzo F, Janne PA. EGFR-mutated oncogene-addicted non-small cell lung cancer: current trends and future prospects. Cancer Treat Rev. 2012;38:416-430

2. van Zandwijk N, Mathy A, Boerrigter L, et al. EGFR and KRAS mutations as criteria for treatment with tyrosine kinase inhibitors: retro- and prospective observations in non-small-cell lung cancer. Ann Oncol. 2007;18:99-103.

3. Haringhuizen A, van Tinteren H, Vaessen HF, Baas P, van Zandwijk N. Gefitinib as a last treatment option for non-small-cell lung cancer: durable disease control in a subset of patients. Ann Oncol. 2004;15:786-792.

4. Paez JG, Janne PA, Lee JC, et al. EGFR mutations in lung cancer: correlation with clinical response to gefitinib therapy. Science. 2004;304:1497-1500.

5. Lynch TJ, Bell DW, Sordella R, et al. Activating mutations in the epidermal growth factor receptor underlying responsiveness of non-small-cell lung cancer to gefitinib. N Engl J Med. 2004;350:2129-2139.

6. Lara-Guerra H, Waddell TK, Salvarrey MA, et al. Phase II study of preoperative gefitinib in clinical stage I non-small-cell lung cancer. J Clin Oncol. 2009;27:6229-6236.

7. Yu J, Kane S, Wu J, et al. Mutation-specific antibodies for the detection of EGFR mutations in non-small-cell lung cancer. Clin Cancer Res. 2009;15:3023-3028.

8. Kawahara A, Yamamoto C, Nakashima K, et al. Molecular diagnosis of activating EGFR mutations in non-small cell lung cancer using mutation-specific antibodies for immunohistochemical analysis. Clin Cancer Res. 2010;16:3163-3170.

9. Gridelli C, De Marinis F, Di Maio M, Cortinovis D, Cappuzzo F, Mok T. Gefitinib as first-line treatment for patients with advanced non-small-cell lung cancer with activating epidermal growth factor receptor mutation: implications for clinical practice and open issues. Lung Cancer. 2011;72:3-8. 
10. Benz MR, Herrmann K, Walter F, et al. ${ }^{18}$ F-FDG PET/CT for monitoring treatment responses to the epidermal growth factor receptor inhibitor erlotinib. $\mathrm{J} \mathrm{Nucl}$ Med. 2011;52:1684-1689.

11. Sunaga N, Oriuchi N, Kaira K, et al. Usefulness of FDG-PET for early prediction of the response to gefitinib in non-small cell lung cancer. Lung Cancer. 2008;59:203-210.

12. Smith IC, Welch AE, Hutcheon AW, et al. Positron emission tomography using $\left[{ }^{18} \mathrm{~F}\right]$-fluorodeoxy-D-glucose to predict the pathologic response of breast cancer to primary chemotherapy. J Clin Oncol. 2000;18:1676-1688.

13. Dose Schwarz J, Bader M, Jenicke L, Hemminger G, Janicke F, Avril N. Early prediction of response to chemotherapy in metastatic breast cancer using sequential ${ }^{18}$ F-FDG PET. J Nucl Med. 2005;46:1144-1150.

14. Terasawa T, Lau J, Bardet S, et al. Fluorine-18-fluorodeoxyglucose positron emission tomography for interim response assessment of advanced-stage Hodgkin's lymphoma and diffuse large B-cell lymphoma: a systematic review. J Clin Oncol. 2009;27:1906-1914.

15. Su H, Bodenstein C, Dumont RA, et al. Monitoring tumor glucose utilization by positron emission tomography for the prediction of treatment response to epidermal growth factor receptor kinase inhibitors. Clin Cancer Res. 2006;12:5659-5667.

16. Ullrich RT, Zander T, Neumaier B, et al. Early detection of erlotinib treatment response in NSCLC by $3^{\prime}$-deoxy- $3^{\prime}$-[F]-fluoro-L-thymidine ([F]FLT) positron emission tomography (PET). PLoS ONE. 2008;3:e3908.

17. Mileshkin L, Hicks RJ, Hughes BG, et al. Changes in ${ }^{18} \mathrm{~F}$-fluorodeoxyglucose and ${ }^{18} \mathrm{~F}$-fluorodeoxythymidine positron emission tomography imaging in patients with nonsmall cell lung cancer treated with erlotinib. Clin Cancer Res. 2011;17:3304-3315.

18. Edet-Sanson A, Dubray B, Doyeux K, et al. Serial assessment of FDG-PET FDG uptake and functional volume during radiotherapy (RT) in patients with nonsmall cell lung cancer (NSCLC). Radiother Oncol. 2012;102:251-257.

19. Zander T, Scheffler M, Nogova L, et al. Early prediction of nonprogression in advanced non-small-cell lung cancer treated with erlotinib by using $\left[{ }^{18} \mathrm{~F}\right]$ fluorodeoxyglucose and $\left[{ }^{18} \mathrm{~F}\right]$ fluorothymidine positron emission tomography. J Clin Oncol. 2011;29:1701-1708.
20. Schaake EE, Kappers I, Codrington HE, et al. Tumor response and toxicity of neoadjuvant erlotinib in patients with early-stage non-small-cell lung cancer. J Clin Oncol. 2012;30:2731-2738.

21. Young H, Baum R, Cremerius U, et al. Measurement of clinical and subclinical tumour response using $\left[{ }^{18} \mathrm{~F}\right]$-fluorodeoxyglucose and positron emission tomography: review and 1999 EORTC recommendations. European Organization for Research and Treatment of Cancer (EORTC) PET Study Group. Eur J Cancer. 1999;35:1773-1782.

22. Junker K, Thomas M, Schulmann K, Klinke F, Bosse U, Muller KM. Tumour regression in non-small-cell lung cancer following neoadjuvant therapy: histological assessment. J Cancer Res Clin Oncol. 1997;123:469-477.

23. Meropol NJ, Schrag D, Smith TJ, et al. American Society of Clinical Oncology guidance statement: the cost of cancer care. J Clin Oncol. 2009;27:3868-3874.

24. Whitson BA, Groth SS, Duval SJ, Swanson SJ, Maddaus MA. Surgery for early-stage non-small cell lung cancer: a systematic review of the video-assisted thoracoscopic surgery versus thoracotomy approaches to lobectomy. Ann Thorac Surg. 2008;86:2008-2016.

25. Gilligan D, Nicolson M, Smith I, et al. Preoperative chemotherapy in patients with resectable non-small cell lung cancer: results of the MRC LU22/NVALT 2/EORTC 08012 multicentre randomised trial and update of systematic review. Lancet. 2007;369:1929-1937.

26. O'Brien ME, Myerson JS, Coward JI, et al. A phase II study of ${ }^{18} \mathrm{~F}$-fluorodeoxyglucose PET-CT in non-small cell lung cancer patients receiving erlotinib (Tarceva): objective and symptomatic responses at 6 and 12 weeks. Eur J Cancer. 2012;48:68-74.

27. Takahashi R, Hirata H, Tachibana I, et al. Early $\left[{ }^{18} \mathrm{~F}\right]$ fluorodeoxyglucose positron emission tomography at two days of gefitinib treatment predicts clinical outcome in patients with adenocarcinoma of the lung. Clin Cancer Res. 2012;18:220-228.

28. Nahmias C, Wahl LM. Reproducibility of standardized uptake value measurements determined by ${ }^{18}$ F-FDG PET in malignant tumors. J Nucl Med. 2008;49: 1804-1808. 